\title{
Hyperprolactinemia in A 15-Year-Old Girl with Primary Amenorrhea
}

\author{
Toshihisa Okada, Soroku Nishiyama and Ichiro Matsuda \\ Department of Pediatrics, Nishibeppu National Hospital (TO), Beppu, Department of Pediatrics, Kumamoto Uni- \\ versity School of Medicine (SN, IM), Kumamoto, Japan
}

\begin{abstract}
It is known that hyperprolactinemia in adolescence is a rare cause of delayed or arrested puberty and growth disturbance. We studied the case of a 15-year-old girl with hyperprolactinemia, obesity, short stature and primary amenorrhea. She had had galactorrhea since 13 years of age, and menarche had not yet been seen by the age of 15 . Her serum prolactin level was extremely high (328 $\mathrm{ng} / \mathrm{ml}$ ), but the other hormones examined were almost within the normal range. The serum prolactin constantly maintained high levels during Insulin+TRH+LH-RH infusion, indicating no reaction to TRH administration. Her sella turcica was slightly flattened on plain X-ray films. Plain and enhanced computed tomograms (CT) of the head were normal, and the pituitary stalk was seen to have shifted to the right on magnetic resonance imaging (MRI). Her serum prolactin level was reduced to $46.1 \mathrm{ng} /$ $\mathrm{ml}$ by treatment with oral administration of bromocriptine $(2.5 \mathrm{mg} /$ day $)$. The level of prolactin was further decreased when the dose of bromocriptine was gradually increased, and galactorrhea almost ceased and menstruation occurred. Prolactinoma in adolescence may also be easily and effectively managed by medical therapy. All clinicians who see patients with arrested puberty and/or primary amenorrhea should therefore be aware of the possibility of this diagnosis.
\end{abstract}

Key words: hyperprolactinemia, primary amenorrhea, prolactinoma, obesity, short stature, bromocriptine

\section{Introduction}

Pituitary tumors in the brain occur most commonly between the ages of 20 and 50, but are rare under 20. Prolactin secreting pituitary adenomas in particular are rare in childhood. Although hyperprolactinemia in adolescence is known to be a recognized cause of delayed or

Received: July 13, 1994

Accepted: July 22, 1996

Pressent address and Correspondence: Dr. Toshihisa Okada, Kanagawa Children's Medical Center, 138-4 Mutsukawa 2-chome, Minami-ku, Yokohama 232, Japan arrested puberty, the clinical presentation and response to treatment in prepubertal or peripubertal patients have seldom been reported in detail. We now report the case of a 15-year-old girl who had hyperprolactinemia, obesity, short stature and primary amenorrhea and was effectively treated with bromocriptine.

\section{Case Report}

The patient was born at 40 weeks of gestation after a normal pregnancy. Her past history was unremarkable. Her younger brother had nocturnal enuresis and learning disability. The 
patient had had galactorrhea since 13 years of age. Menarche had not yet been seen by the age 15 though her breast development started at 10 years of age. No drugs which may have caused hyperprolactinemia were taken. She was first seen at the age of 15 years and 6 months because of obesity. Her body weight was $57.3 \mathrm{~kg}$ (obesity index $34.1 \%$ ). In addition, she was of short stature with a height of $145.6 \mathrm{~cm}$ (2.3SD). Pubertal stages according to Tanner were axillary hair IV, public hair IV and breast V. Lungs, heart and abdomen showed nothing in particular. There were no gynecological abnormalities in the internal and external genital organs. Slight depression of the inner isopter of the left eye was noted. Her intelligence quotient (IQ) was 114.

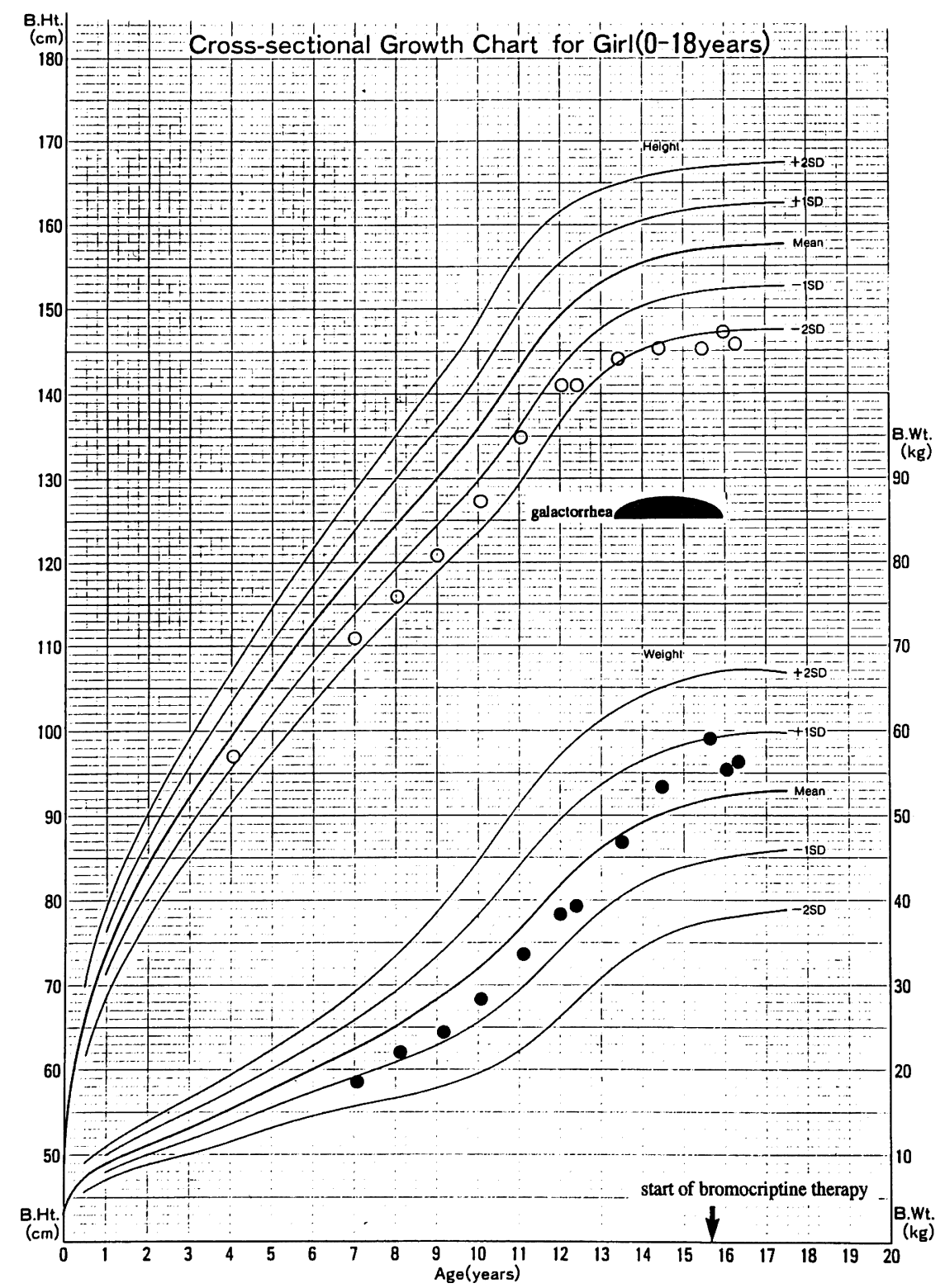

Fig. 1 Growth curve of the patient. 
Her growth curve is shown in Fig. 1.

\section{Laboratory Results}

Routine laboratory examination revealed no significant abnormalities in hematometry, hemogram, blood chemistry or urinalysis. Bone age was 14.3 years (TW2 standardized for Japanese) at her chronological age of 15.6 years. Her karyotype was $46, \mathrm{XX}$.

The endocrinological data are shown in Table 1. Serum hormone levels of the thyroid, parathyroid, adrenal cortex and gonads were within the normal range, but serum prolactin noticeably increased at $328 \mathrm{ng} / \mathrm{ml}$.

In the oral glucose tolerance test, the time course of the blood sugar level was normal except at $30 \mathrm{~min}$, but the serum insulin level was high throughout the test. The serum prolactin level constantly remained high during insulin + TRH + LH-RH infusion, indicating no reaction to TRH stimulation (Table 2).

The sella turcica seemed slightly flattened on plain X-ray film. The plain and enhanced CTs were normal, but the pituitary stalk was shifted to the right on MRI (Fig. 2). No signs which suggested the presence of a tumor mass were noted on either CT or MRI. No abnormal uptake was found on the systemic gallium scintigram.

\section{Clinical course}

The clinical course is shown in Fig. 3. Two weeks oral administration of bromocriptine mesilate (BCM) at a dose of $2.5 \mathrm{mg} /$ day was initiated, and the serum prolactin level decreased from 328 to $46.1 \mathrm{ng} / \mathrm{ml}$, but galactorrhea persisted. Subsequently, the dose of BCM was gradually increased, and two months after the initiation of treatment, when the serum prolactin level decreased to $16.1 \mathrm{ng} / \mathrm{ml}$, galactorrhea completely disappeared. Four months later, when the dose of BCM reached $7.5 \mathrm{mg} /$ day, menarche occurred.

\section{Discussion}

Hyperprolactinemia due to a prolactin secreting pituitary adenoma is now a well recognized cause of secondary amenorrhea in women. Such patients often respond well to orally active dopamine agonists such as BCM, which usually lead to normal serum prolactin levels and normal gonadal function. In the majority of cases, shrinkage of the adenoma occurs, even in

Table 1 Endocrinological data

\begin{tabular}{|c|c|c|c|c|c|}
\hline \multicolumn{3}{|c|}{ <Pituitary hormones > } & \multicolumn{3}{|c|}{$<$ Adrenal hormones $>$} \\
\hline ACTH & 13 & $\mathrm{pg} / \mathrm{ml}$ & dopamin & 12 & $\mathrm{pg} / \mathrm{dl}$ \\
\hline PRL & 328 & $\mathrm{ng} / \mathrm{ml}$ & adrenalin & 36 & $\mathrm{pg} / \mathrm{ml}$ \\
\hline $\mathrm{ADH}$ & 1.1 & $\mathrm{pg} / \mathrm{ml}$ & noradrenalin & 174 & $\mathrm{pg} / \mathrm{ml}$ \\
\hline Oxytocin & $<3.0$ & $\mu \mathrm{U} / \mathrm{ml}$ & $\begin{array}{l}\text { urine } 17 \mathrm{KS} \\
\text { urine17OHCS }\end{array}$ & $\begin{array}{l}8.6 \\
4.1\end{array}$ & $\begin{array}{l}\mathrm{mg} / \text { day } \\
\mathrm{mg} / \text { day }\end{array}$ \\
\hline \multicolumn{6}{|c|}{$<$ Thyroid · Parathyroid hormones $>$} \\
\hline $\mathrm{T}_{3}$ & 145 & $\mathrm{ng} / \mathrm{dl}$ & & & \\
\hline $\mathrm{T}_{4}$ & 8.8 & $\mu \mathrm{g} / \mathrm{dl}$ & \multicolumn{3}{|c|}{ <Gonadal hormones> } \\
\hline$f-T_{3}$ & 3.7 & $\mathrm{pg} / \mathrm{ml}$ & $\mathrm{E}_{2}$ & 26.9 & $\mathrm{pg} / \mathrm{ml}$ \\
\hline$f-T_{4}$ & 1.1 & $\mathrm{ng} / \mathrm{dl}$ & Progesterone & 0.2 & $\mathrm{ng} / \mathrm{ml}$ \\
\hline TBG & 30.8 & $\mu \mathrm{g} / \mathrm{ml}$ & Testosterone & 57.1 & $\mathrm{ng} / \mathrm{dl}$ \\
\hline HS-PTH* & 360 & $\mathrm{pg} / \mathrm{ml}$ & & & \\
\hline Calcitonin & 14 & $\mathrm{pg} / \mathrm{ml}$ & $\begin{array}{l}\text { <others> } \\
\text { IGF-1 }\end{array}$ & 1.82 & $\mathrm{U} / \mathrm{ml}$ \\
\hline \multicolumn{3}{|c|}{ HS-PTH*: highly sensitive-PTH } & \multicolumn{3}{|c|}{ (acid-ethanol extraction) } \\
\hline
\end{tabular}


Table 2 Endocrinological tests <oGTT (1.75 g/kg standard body weight>

\begin{tabular}{lrrrrrr}
\hline (min.) & 0 & 30 & 60 & 90 & 120 & 180 \\
\hline BS (mg/dl) & 87 & 160 & 147 & 83 & 109 & 106 \\
IRI $(\mu \mathrm{U} / \mathrm{ml})$ & 18 & 140 & 200 & 54 & 84 & 95 \\
\hline
\end{tabular}

$<$ Insulin, TRH and LH-RH infusion test >

\begin{tabular}{lccccc}
\hline (min.) & 0 & 30 & 60 & 90 & 120 \\
\hline BS (mg/dl) & 83 & 41 & 69 & 80 & 84 \\
GH (ng/ml) & 0.20 & 0.42 & 18 & 10 & 2.3 \\
Cortisol ( $\mu \mathrm{g} / \mathrm{dl})$ & 9.4 & 10.0 & 15.6 & 13.2 & 10.4 \\
& & & & & \\
TSH ( $\mu \mathrm{U} / \mathrm{ml})$ & 1.8 & 20.8 & 15.4 & 11.5 & 8.1 \\
PRL (ng/ml) & 286.0 & 291.0 & 282.0 & 288.0 & 277.5 \\
& & & & & \\
LH (mIU/ml) & 2.9 & 54.5 & 43.0 & 36.0 & 29.4 \\
FSH (mIU/ml) & 5.2 & 20.8 & 19.2 & 18.7 & 17.3 \\
\hline
\end{tabular}

$<$ rapid ACTH test>

\begin{tabular}{lrrr}
\hline (min.) & \multicolumn{1}{c}{0} & \multicolumn{1}{c}{30} & \multicolumn{1}{c}{60} \\
\hline $17 \alpha-O H P(\mathrm{ng} / \mathrm{ml})$ & 0.2 & 1.3 & 1.6 \\
cortisol $(\mu \mathrm{g} / \mathrm{dl})$ & 12.3 & 21.5 & 25.0 \\
DHEA $(\mathrm{ng} / \mathrm{ml})$ & 6.1 & 8.1 & 10 \\
\hline
\end{tabular}

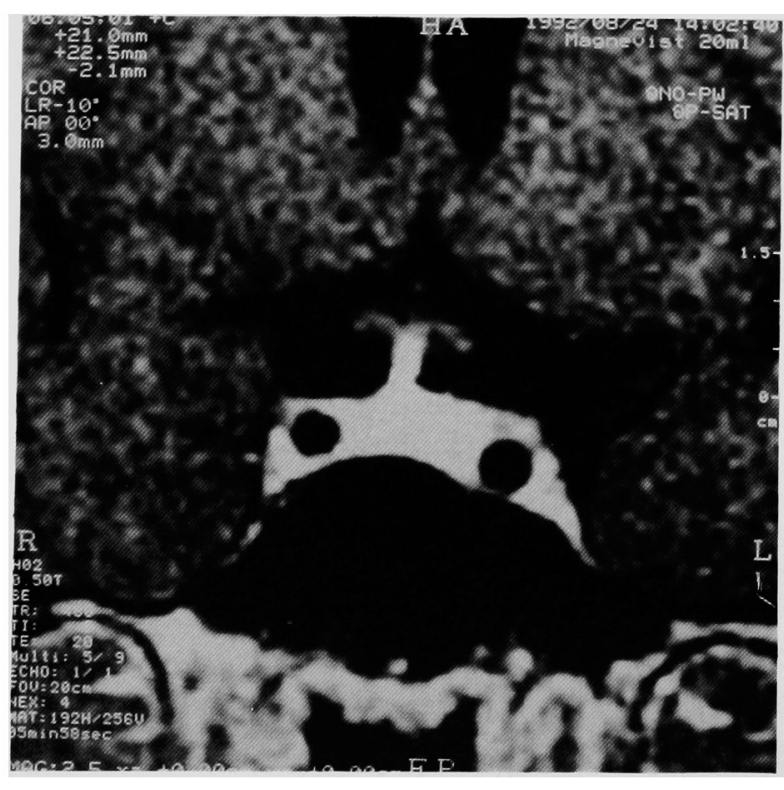

the presence of a large extrasellar extension.

We saw hyperprolactinemia in a 15-year-old girl with primary amenorrhea, obesity and short stature. It was suggested that she had a prolactin-producing microadenoma, because brain imaging tests failed to show evidence of a tumor mass. It was also assumed that her hyperprolactinemia began at about 13 years of age, judging from the onset of her galactorrhea. Howlett et al. (1) reported 14 peripubertal cases of prolactinoma, of which nine cases had macroadenomas demonstrated by CT scan and/or pneumo-

Fig. 2 MRI of the head. The pituitary stalk had shifted slightly to the right. 

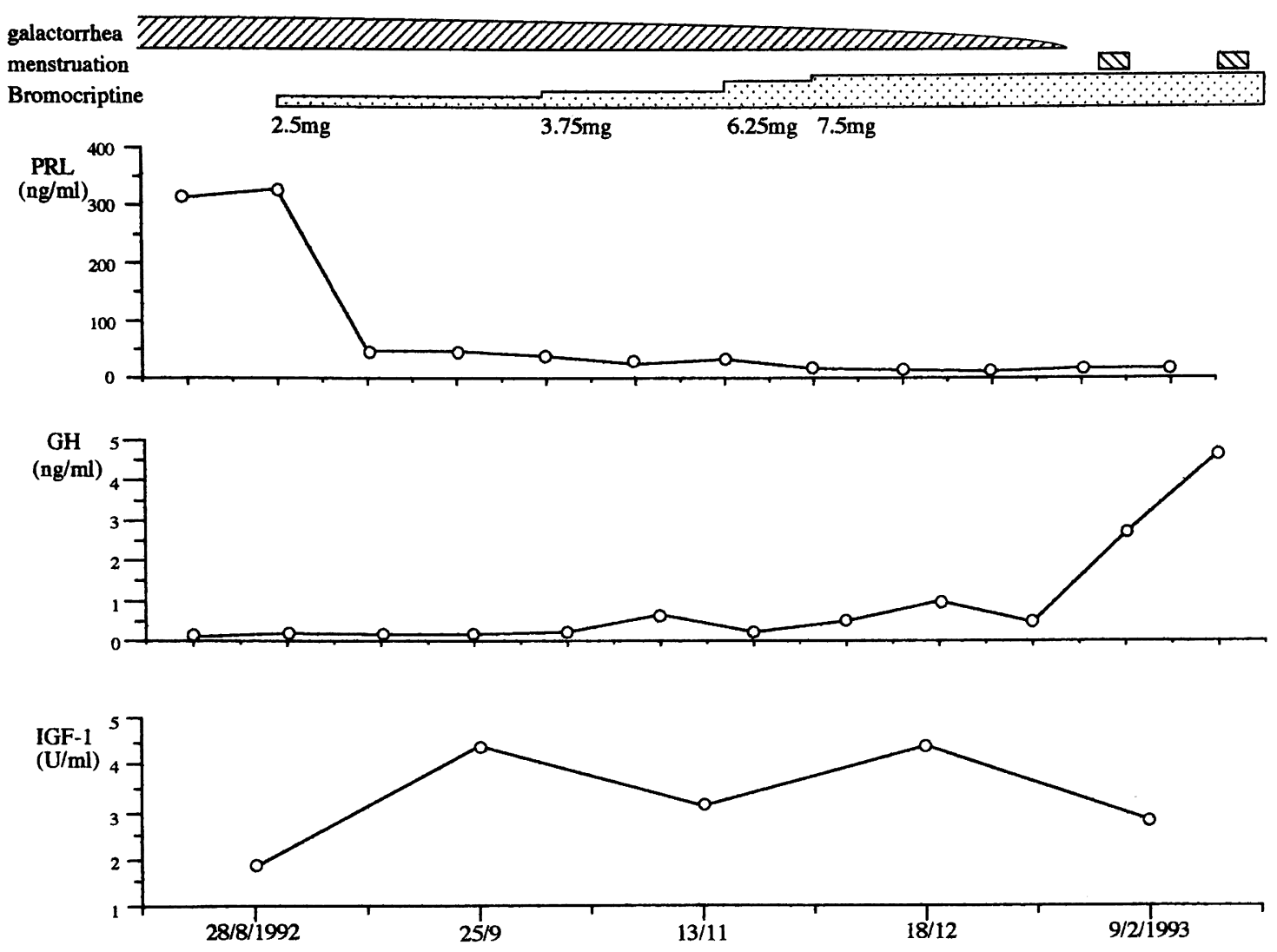

Fig. 3 Clinical course.

encephalography, and the other five had microadenomas. In the brain tumor registration in Japan between 1969 and 1981, 3,152 cases were registered under age 14 and only $36(1.1 \%)$ of them had pituitary adenoma (2). Among all the cases of prolactinoma only $0.47 \%$ of them were under age 20. Pre- and peripubertal cases of prolactinoma are therefore rare. We should therefore observe such cases very carefully, as they may reveal certain clinical features which are specific to their age and are not fully understood.

We now discuss the causes of her short stature. Although we cannot fully exclude the possibility that her short stature may be simply explained by a constitutional (non-pathological) process, her height seems to deviate from her own growth channel at 13 years of age when galactorrhea occurred coincidentally. Jungmann et al. (3) suggested that GH secretion is impaired at the pituitary level by feedback stimulation of an inhibitory dopaminergic mechanism by prolactin excess. Howlett et al. (1) found impaired GH secretion in eight out of 14 cases of prolactinoma, and GH responses improved with bromocriptine in eight cases. In the present case, however, there seems to be no definite evidence of subnormal $\mathrm{GH}$ secretion, whereas slightly low plasma IGF-1 (1.82 U/ml) was noted when compared with the levels after therapy. Irrespective of its real cause, growth disturbance is a clinically important feature in childhood prolactinoma.

Hyperprolactinemia is known to be associated with a high frequency of obesity (4). As not only growth disturbance and galactorrhea but also 
obesity started simultaneously at about 13 years of age in the present case (Fig. 1), hyperprolactinemia may also be causally related to obesity. Improvement in obesity after the induction of therapy also supports this view, but the pathogenesis of this obesity is still unclear.

In this case, her puberty started with breast development at ten years of age and reached nearly adulthood on appearance, but she had not had menarche. We guess that her hyperprolactinemia had already been present by that time. It appears that hyperprolactinemia can cause several different symptoms according to the different times of onset of hyperprolactinemia, and there include delayed puberty, arrested puberty, primary amenorrhea and secondary amenorrhea.

Medical treatment with BCM was effective in the present case, though therapeutic results have seldom been reported in childhood prolactinoma with $\mathrm{BCM}$, especially when microadenoma is suspected.

In summary, prolactinoma in adolescence is a rare cause of delayed or arrested puberty, and it may also cause short stature and/or obesity. Furthermore, it may be effectively managed by medical therapy. All clinicians who see patients with these symptoms should therefore be aware of the possibility of this diagnosis.

\section{References}

1. Howlett TA, et al. Prolactinomas presenting as primary amenorrhea and delayed or arrested puberty: Response to medical therapy. Clinical Endocrinology 1989; 30: 131-40.

2. The committee of brain tumor registry in Japan. Brain tumor registry in Japan 1987 in Japanese.

3. Jungmann $\mathrm{E}$, et al. Evidence for functional impairment of growth hormone secretion in prolactinoma. In: Prolactinomas, an interdisciplinary approach. Auered LM, New York 1985: 147-53.

4. Creemers LB, et al. Prolactinoma and body weight: A retrospective study. Acta Endocrinologica (Copenh) 1991; 125: 392-6. 